\title{
EL DIARIO COMO UN HOMENAJE INMENSO
}

José María Espinasa*

Origen anecdótico: un libro que parece una broma

Ojeando las novedades en las mesas de una librería en la ciudad de México llamó mi atención, a fines del mes de enero, un enorme libro, casi tan ancho como alto, un cubo de 1700 páginas que llevaba el escueto título de Borges, firmado por Adolfo Bioy Casares. De más está decir que el aspecto del volumen recordaba aquellas licoreras disimuladas que el mal gusto puso de moda en los años sesenta, y que -transformados por el culto kitsch- hoy son objetos de verdadero fetichismo. Del libro se había tenido noticias por los periódicos a raíz de su presentación en Argentina-donde de inmediato despertó

* Escritor. polémica- y en España -donde fue recibido reverencialmente.

El aspecto físico del libro, junto al título y el autor, resultaban magnéticos para la mirada. Borges y Bioy por separado son muy atractivos, pero juntos más aún -las obras que escribieron en colaboración me parecen extraordinarias- $y$ forman una extraña pareja, ejemplo de una amistad nada frecuente entre los hombres de letras. Pero al gesto inicial siguió en mí, apenas abierto, el de dejarlo en su lugar, convencido de que el precio sería inalcanzable para mi bolsillo. Al levantar la vista me encontré con el encargado de la librería, uno de los pocos libreros con conocimiento que quedan, que me dijo, con la exacta terminología mexicana: 'padre, ¿verdad?'. Le contesté que sí, pero que debía ser carísimo. Me dijo que no y me mostró el precio al dorso. 
En efecto, supongo que gracias al papel excesivamente poroso y al enorme tiraje que se debió hacer, era de verdad muy barato para su número de páginas. Y me lo llevé con la convicción de que sería una lectura para muchos años.

En realidad se transformó en una caja de Pandora, ya que libros así son muy raros en la literatura. En general, después de la muerte de Bioy, en 2000, y también desde algunos años antes, se habían publicado muchos títulos que se sumaban a su bibliografía crítica y testimonial, sin aportar gran cosa, rescatados del olvido por la coyuntura o fabricados al calor de la fama del gran escritor que se aproximaba a su muerte, como sobreviviente-además-de un grupo o generación excepcional. Y el párrafo sirve para hablar de ambos: Borges y Bioy. Si la obra narrativa del segundo, a la que debe su fama, lo hacía aparecer ante nuestros ojos como una máquina de la escritura a la manera deleuziana de entender el término, las noticias aparecidas sobre su diario despertaban curiosidad en los lectores, voracidad entre los editores y perplejidad entre los críticos, sobre todo por su extensión y constancia.

La bibliografía sobre Borges es abundante, abundantísima; a él le gustaría que la hubiera calificado de infinita, y cuenta en su haber con títulos célebres, de Sucre, Rodríguez Monegal, al grado de que su nombre es ya una industria aparte en el mundo editorial, empedrada con líos legales, manuscritos desempolvados, rescates, testimonios no siempre bien intencionados, apócrifos, imposturas y posturas metodológicas de todo tipo. Es difícil pensar ahora en escribir sobre el autor de El aleph y decir algo nuevo, original o sorprendente, y se tiene siempre la sensación de que se lee una glosa de algo ya dicho. Pero si alguien podía hacerlo -renovar la imagen- era precisamente su gran amigo Adolfo Bioy Casares. ¡Y de qué manera lo hizo!

Me quiero detener un poco en el asunto de la bibliografía borgeana. No es de extrañar que un autor tan importante - un verdadero monstruo literario- concite a tantas plumas, con ideas y estilos tan diversos; lo curioso es que su vida - una vida, por cierto, que no parece tener grandes atractivos- llame tanto la atención e incluso proponga visiones diferentes, muchas veces irreconciliables y cada vez menos certificables, como si esa abundancia de enfoques biobibliográficos termine por hacer de la vida una ficción más. Y en medio de esa incertidumbre que alcanza a veces tonos muy subidos, incluso en tribunales, cae este meteorito que es el libro de Adolfo Bioy Casares. Y su impacto amenaza con 
extinguir la vida bibliográfica de todos los habitantes-dinosaurios del librero-planeta Borges. Y no porque el libro de Bioy imponga una verdad anecdótica o crítica, sino porque de suyo no puede dejar de hacerlo. ¿Qué queda por decir sobre el escritor argentino después de este tomo? Queda mucho, claro, ningún libro, más aún cuando es bueno como es el caso, impide sino que potencia nuevas interpretaciones.

Lo curioso es que, caído el meteorito, en realidad las cosas siguen igual que antes en lo que se refiere al oficio de los biógrafos, ya que Bioy no hace una biografía sino que publica las páginas de su diario que hablan de Borges, y hace una obra maestra del género casi sin darse cuenta, aunque no sin proponérselo. Sus páginas biográficas no habían presagiado el resultado de este Borges, pues ni parecían muy inspiradas ni le entusiasmaba mucho el asunto. Bioy Casares es ante todo un narrador extraordinario, y al interior de sus obras la melancolía proustiana era apenas un barniz (más allá de que ciertos libros, por ejemplo Los Bioy, quieran dar a entender un parentesco espiritual más profundo).

Ustedes habrán oído muchas veces, yo mismo lo sostengo en diferentes lugares, que el diarismo es un género que permite al escritor, pero sobre todo al lector, ser eventual y azaroso, picotear en una página o en un tema sin anclarse al corpus reunido bajo las tapas ¿Quién ha leído, por ejemplo, el Diario de Anais Nin en forma ordenada y exhaustiva? Me imagino que nadie, ni siquiera un profesor norteamericano que quiera escribir su tesis sobre ella. Y supongo, lo he oído a varias personas, también se dirá de este Borges, que no se trata de una obra para leerse completa y de una sentada. Pues así la leí yo y no me arrepiento (la sentada, claro, es de varios meses), y creo que vale la pena leerlo así, porque la sutil diferencia que se va dando de las primeras páginas a las últimas, esa sí es proustiana.

La maledicencia que recorre las conversaciones entre los dos escritores es una lección de literatura, ya que cualquier comentario tiene que ser, antes que nada, chispeante, inteligente, pleno de humor y cuando se deslizan comentarios dictados sólo por la animadversión o el rencor, se nota, el brillo se apaga, burbujea menos la frase, y ellos -ambos- se dan cuenta. Así, contrastar los juicios vertidos en prólogos, ensayos y comentarios públicos, con los que hay en este libro, es un asunto vano, ya que no se trata ni de buscar contradicciones ni de develar la hipocresía, tentación de tantos tontos: no la hay, sino de entender el lugar desde el cual se habla. Quiero aclarar tam- 
bién que no se trata del terreno de la intimidad, ya que la sobremesa es un espacio público, sino de entender que si el público para Borges es Bioy o al revés, el tono de charla es distinto que si se trata de una conferencia, no más sincero sino más inteligente y festivo, provocador en función de una hermandad establecida por vaya a saber usted qué hados misteriosos.

\section{El lugar desde el cual se escribe}

Entiendo perfectamente a fanáticos de Borges señalar que Bioy no tenía derecho a hacer público a ese Borges. La verdad, creo que hay que agradecerle que su admiración intensa y su amistad no lo obnubilen en busca de una hagiografía, que se pueda ver a ese Borges que se mea fuera de la taza o que puede salir a la playa sin ponerse el traje de baño -"estás en bolas" le recrimina Bioy- suma al texto una más de sus excepcionalidades. Tampoco oculta sus simplificaciones, las de ambos, en el terreno político. A los mexicanos, por poner un ejemplo, nos molesta la trivialidad con que escriben una carta en apoyo a Díaz Ordaz cuando la matanza del 68, ¡sólo porque Elena Garro se los pide! Se puede pensar que Bioy quería y admiraba tanto a Borges que hasta sus más tontas posturas -su racismo, por decir algo- le parecían inteligentes, pero no se trata de eso, sino de hacer una bitácora tan exhaustiva como se pueda, de esa 'máquina literaria', de 'su' amigo. Ese su entrecomillado no indica una pertenencia que se confunda con propiedad, pocos como él hicieron cosas para que Borges fuera de todos (y en esa vía se inscribe este tomo).

Retrospectivamente se podría decir que en Borges no fueron dos escritores que se hicieron amigos sino que fueron dos amigos que escribían para conocerse y tener esa amistad. Si sus críticas a Cervantes, a Quevedo, a Góngora entre nosotros, o a Shakespeare en otros dominios lingüísticos, pueden parecer boutades de niños traviesos, sin dejar de serlo son argumentadas con tal inteligencia que resultan ejemplares de cómo vivían la literatura. La cruel mirada sobre sus contemporáneos no es ni más ni menos inclemente que la que tienen sobre los clásicos, el tiempo -dirían, y hay que recordar que ambos fueron longevos- no es razón para la indulgencia.

Lo que se va configurando en las infinitas y a la vez siempre pocas páginas del libro es una manera de entender el hecho literario -lectura y escritura- a través de un diálogo privilegiado y en un momento excepcional de la literatura argentina 
(con un curioso vacío a escritores de otras lenguas, que sólo aparecen cuando o se arraigan en Argentina o su aparición por esos lares tiene algo que ver con ellos mismos). Bioy tuvo, desde la cuna, una situación privilegiada y no siente la menor tentación de lamentarlo; en un determinado momento del libro dice algo así como que las buenas personas (y entiende por esto: buenos escritores) son aquellos que se gastan la herencia que les dejan sus ancestros sin necesidad de mancharse las manos con el trabajo. Y hay que entender que herencia aquí no designa sólo lo económico. Pero a lo largo del libro queda claro que él y Borges trabajaron mucho -planeaban colecciones, hacían antologías, daban cursos y conferencias, publicaban artículos, escribían a cuatro manos, traducíany sus obras no son en ambos casos de las que se pueden calificar de breves. Desde el lado de la literatura no descansaban un momento, y si esto no es considerado directamente trabajo es -curiosamente- por una idea de clase de lo que es un escritor. Que esto también marca sus inclinaciones políticas, muchas veces no sólo lejanas sino antitéticas de sus lectores naturales, es cierto, pero al igual que con los juicios literarios hay que tomarlos en el sentido de un pensamiento en circunstancia, muy orteguiano, a pesar de que la concepción filosófica del español les resultara insoportable.

En esas páginas uno puede espigar cientos de aforismos de gran ingenio, a veces de sorprendente sencillez (cuando le preguntan a Borges qué razones tiene para decir que no le daría el Nobel a Alberti contesta: "haberlo leído"); anécdotas de una vida literaria como la de cualquier otro lugar y tiempo, pero que se ilumina por la ironía de ambos conversadores (y, a veces, poco, por la presencia de otros: Peyrou, Bianco, Silvina Ocampo), con las mismas rencillas caseras, envidias aldeanas, sinsentidos de grupo, dibujados en viñetas que, sin embargo, no cansan. Hacer un libro de chismes es fácil, hacerlo de 1700 páginas y que sea no sólo bueno sino extraordinario es un verdadero milagro. Y es que algo de milagroso tiene el volumen de Bioy sobre Borges: lo primero, la persistencia de una amistad tan intensa entre dos personalidades tan fuertes.

Durante años se ha hablado del autor de La invención de Morel como un apéndice de la estética de Borges (hay quien lo ha llamado un Borges diluido). Este libro muestra divergencias y diferencias más profundas de lo que se cree, incluso en el género mismo el novelista frente al cuentista, el cuentista frente al ensayista, el diarista frente al poeta. Nada más lejano -ni siquiera 
la novela- de la intención de Borges que el diario, y helo aquí personaje de uno extraordinario.

Un punto que nos daría tela de dónde cortar es el de la incomprensión. Cuando rechazan autores en cierta manera consagrados, y literalmente los hacen pedazos, como a Quiroga y Artl en el contexto hispanoamericano, o a Goethe y Baudelaire en el universal, lo que sorprende no es la incomprensión y el equívoco sino las 'buenas razones' que tienen para hacerlo. Elogian a Arreola pero detestan a Felisberto Hernández (cómo no se dieron cuenta del parentesco). Y en el colmo del asunto se la pasan señalando los errores de Shakespeare para luego ponerse a traducirlo. Esto sólo puede sorprender a un lector que crea que la literatura está hecha de posiciones inamovibles y no de instantes de gozo siempre (y afortunadamente) elusivos, y nunca lastrados por el fetiche del autor y ni siquiera del texto, en la memoria los citan de una u otra manera sin sufrir por ello.

La contradicción se manifiesta en el hecho de que siendo ambos escritores en más de un sentido muy modernos sus gustos más que clásicos son conservadores (detestan a Joyce, de Beckett creo que hablan una sola vez y mal), pero en realidad más que un gusto en sentido estricto lo que tienen es un placer en la lectura, por eso hoy puede gustarles algo que mañana o dentro de treinta años no. Les gusta leer (y por eso leen muchos y mediocres trabajos para concursos de los que son jurados) y transforman aquello que leen en literatura-frases hechas, expresiones idiomáticas, refranes, gazapos, muletillas-, en hecho literario, sea de Homero o del vecino. Y el placer es maledicente. Nos podemos preguntar -no sé si algún día lo sabremos- sobre lo que Bioy (o el editor Martino, seguramente por indicación de Bioy) quitó del Diario. Es evidente, por ejemplo, que hay contadas alusiones a la vida sentimental de ambos, y la mayoría de las veces sólo cuando adquieren un contorno anecdótico, y que -de entender el texto como totalidad-no hay entre ellos casi nunca confesiones. Es razonable suponer que sí las hubo y que el que no estén nos dice cosas (al igual que si nos equivocamos y no las hubo, también nos dice cosas este hecho). Se puede formular con una paradoja interesante: es muy personal pero nada íntimo, al grado de que entendemos lo íntimo como algo que en el texto no tiene (no debe tener) lugar.

A su vez no hay en el diario pensamientos profundos, para ellos el calificativo de profundos lleva inevitablemente una noción de falsedad, de pedantería; tampoco hay reve- 
laciones notables -las fobias y los agrados eran ya más o menos conocidas- y menos aún revelaciones de hechos que hubieran permanecido ocultos y que cambiaran nuestra concepción de ambos autores. Y eso ocurre porque la revelación está antes del texto: Borges se revela como es monstruo literario de inmediato a los ojos del incipiente escritor casi adolescente. El Bioy antes de Borges es para mí un misterio, oigo hablar de esos libros tan malos, pero nunca he tenido uno en las manos o ante la vista, no conozco a nadie que los haya leído o los haya tenido en sus manos, y eso los hace adquirir un carácter casi mítico: el caos antes del orden que impone la amistad con Borges. Pero ese Bioy pre-Bioy no es sino un telón de fondo para mejor delinear el personaje. Así, el diario es una manera de desplegar la revelación-que, según la mayoría de los casos, es instantánea, relampagueante y con poca duración-. Ésta en cambio ilumina cincuenta años de la vida de ambos.

En cierta forma se trata de un libro con tantas razones que se vuelve inexplicable: era lógico que se escribiera, es lógico que moleste a tirios y troyanos, y que no deje contento a nadie; es también lógico que sea tan extenso y fabricado con chismes, pero lo que no es lógico es que sea tan bueno, todo hacía prever un fra- caso. Las prosas biográficas del autor no habían sido muy afortunadas y su elegante estilo no basta para justificar libros que parecen escritos un poco sin un motivo que no fuera otro que el comercial. Podemos suponer hipótesis biográficas: si Borges hubiera muerto antes Bioy habría dejado de estar-al menos ante los críticos y los lectores-a su sombra, pero este libro lo que nos dice es que no hay mejor lugar que bajo esa sombra, más allá de vanidades personales (ambos las tenían en cantidad) y que si el autor había descubierto 'un reino que sí estaba para él' (el de Borges) resultaría absurdo negarse a habitarlo.

El juego borgiano del otro, pero 'el otro Borges', es decir otro yo mismo, es fruto de esa dialéctica de las dos orillas: no se puede estar en las dos al mismo tiempo, y sin embargo Bioy lo intenta con este libro desmesurado. Como no precisar el sentido de la amistad sino a través de ese acontecer cotidiano, pero sin insuflarle nada más, puramente cotidiano, ya que así se vivió. En la pluma de un alter ego tan distante (en tanto otro) como cercano (en tanto Bioy) Borges deja de ser el fantasma de un fantasma para ser plenamente de carne y hueso, para él de letras, sílabas, frases, ritmos. Al ser tan admirativo pero poco hagiográfico lo sitúa en una eternidad construida sobre la literatura, sin apelar a bondades 
más -o menos- humanas. Cuando se habla, sobre todo en el siglo de oro, de esos recitativos iniciados por un personaje y terminados por otro y cuya transposición de la voz ocurre a la mitad de un verso, uno no sabe cómo explicarlos, no le basta la métrica, pero tampoco la metafísica. Algo así ocurre aquí. A lo largo del diario, y de la obra de ambos, Boswell y sus Conversaciones con Johnson son casi un leimotiv, pues en efecto es otro libro donde, sin importar jerarquías, eso ocurre de forma milagrosa.

Vuelvo a insistir que esa condición inexplicable termina por ser milagrosa: no es frecuente -ya se dijo- una amistad tan larga entre escritores de la misma edad, menos entre autores de dos generaciones, en donde la amistad tiende a volverse magisterio; también es raro que esa relación se de, y lo subrayo, entre autores tan intrínsecamente diferentes. Pongo una diferencia clara: su relación con las mujeres. Mientras Borges, a pesar de que tuvo varias relaciones sentimentales, mantenía una torturada correspondencia con ellas y son conocidos sus epigramas contra la sexualidad, Bioy Casares se transmutaba en un Don Juan lúdico que iba de amante en amante sin jamás romper con Silvina Ocampo, algunos años mayor que él. En el diario se insinúan apenas esas diferencias, pero lo suficiente como para hacer sentir lo cuidadoso que era Bioy en un asunto que sabía conflictivo. ¿Por eso uno es cuentista y el otro novelista? La pregunta, no por ser un poco absurda, deja de tener interés.

Ya en un terreno más espeso esa diferencia lleva a analizar la relación que tenían con el otro, áspera en Borges, lúdica en Bioy, pero en ambos sin darle una gran consistencia emotiva, salvo -menuda salvedad- entre ellos dos, por lo que se desprende de este libro. En un momento del texto se refiere que Borges, enojado por la pregunta de un reportero - ¿está usted más allá del bien y del mal?- le señala a Bioy ¿no se dará cuenta de que estar más allá del bien y del mal es estar ya del lado del mal? Se lo preguntaba a alguien que encantado habría contestado que sí, que estaba más allá. Cuando se leían las obras de Bioy siempre se tenía una sensación curiosa: qué escritor tan bueno y tan superficial, ciertos elementos triviales parecían distanciarnos de su transparencia estilística. Cuando en su Autobiografía, refiere que tiene que vender una cámara de fotografía porque el terrateniente dueño de inmensas haciendas está en la ruina, una sonrisa entre compasiva y escéptica viene a cuento. Tal vez las más estremecidas páginas de Bioy sean las finales de 
este diario y proyectan su resplandor sobre la revelación descrita en todas las anteriores.

Hasta ahora lo curioso es que aceptamos el hecho de que el libro está armado como una suma de infidencias, pero realmente ¿cuál recordamos? La mezquindad de algunos, el miedo de otros, el oportunismo de los de más allá son más bien convencionales; lo que le da un tono único y diferente es el comentario sagaz y casi siempre sarcástico, el tamaño de la incomprensión -pongo un ejemplo- mientras en su diario Gombrovicz, más allá de la antipatía, entiende la importancia de Borges, para Borges en cambio la obra del polaco es no sólo insignificante sino molesta.

Los chismes son en realidad epigramas afilados, viñetas del costumbrismo literario en que estuvieron inmersos; el texto no puede tomar otro vuelo porque la carne es el diálogo entre ambos, Bioy y Borges, hechos el uno para el otro, en una condición que ese 'entre' subraya, de permanente exterioridad. Recurro otra vez a la comparación con el ya mencionado de Grombrovicz: mientras éste dedica densas páginas a comentar una lectura, por ejemplo la de Simone Weil, Borges despacha a autores de todo tipo de nivel, tono y jerarquía en un par de frases.
La manifestación de gustos (más bien disgustos) no representa aquí la amargura tan frecuente del escritor resentido (vaya usted a saber la razón, pues no podía ser la falta de reconocimiento para ambos), sino una manera de ser no tanto hipercrítica, tal vez ni siquiera exigente, sino un simple proceso de identificación $\mathrm{y}$, con los años, reforzamiento de la amistad. El placer que se desprende del comentario ágil y la respuesta ingeniosa es impagable, se esmeran como esgrimistas en un desafío sin riesgos, claramente hedonista y en el que, al menos en el libro y como otra muestra de elegancia quien lo escribe casi siempre cede la palabra a su admirado y entrañable amigo. Quien se encoleriza por las muchas veces arbitrarios juicios de Borges ratificados por Bioy se olvida que esa condición-lo arbitrario- es lo que le otorga libertad a la inteligencia.

Un par de bailarines del ingenio que se entusiasman en el paso que permite al otro hacer el suyo más vistoso. Ignoran a los otros muchas veces, bailan de una manera no tanto egoísta sino ajena precisamente al reconocimiento público y más complacidos en reconocerse entre ellos. Pero también se la pasan planeando cosas para ese mundo al que supuestamente son ajenos o ignoran; les debemos antologías prodigiosas, prólogos y ensayos célebres, colec- 
ciones de alcance masivo, la gran difusión de la novela policíaca en castellano, género que arraigó más entre los escritores latinoamericanos que entre sus lectores; traducciones notables de algunos textos clásicos y de muchos antes desconocidos en castellano. Borges y Bioy representan una idea de la literatura deslumbrante e irrepetible y en el diario de Bioy conocemos su interior-que no su interioridad-y se pueden apreciar más tanto los matices como los movimientos de bulto. Como en un juego de muñecas rusas, se desmonta la pertenencia: la relación distante, pero creo que más intensa de lo que el libro deja traslucir, con la revista Sur y con su capitana Victoria Ocampo, los amores castigadores con Mallea, Bianco, Mujica Lainez y otros, el anglicismo o el afrancesamiento, su desprecio por las vanguardias, su visión de clase. Es como tener una lámina biológica en tres dimensiones de un cuerpo literario, con su sistema nervioso, los músculos y las venas, las vísceras y las articulaciones, los huesos y las glándulas y funcionando en vivo y en directo.

Algunos críticos -y en cierta manera el mismo Borges- mostraron sorpresa cuando ciertos textos suyos eran tomados como leitmotiv, metáfora, ilustración o ejemplo de un discurso filosófico. El caso más celebre es Foucault y Las palabras y las cosas. Y no sólo porque la mayoría de las veces, al volver la filosofía ficción, Borges inevitablemente la parodia sino porque en ese afán paródico, consciente o no, lo que ocurre es que el discurso se muestra como mecanismo y pierde toda profundidad. Eso lo transmite claramente el diario de Bioy, no hay nunca una discusión de verdaderas ideas, sino en todo caso de oficio y posiciones. Por eso Borges ni siquiera piensa en lo ridículas que resultan no sólo algunas de sus posturas políticas sino incluso sus sarcasmos racistas y sexistas. Se entiende, incluso, el rechazo al discurso pero no lo ajeno que estaba (n) a la densidad de la experiencia.

De allí que Borges sea un autor peligroso: su brillantez está fuera de duda, al igual que su genio, pero inquieta no tanto la frialdad sino la insensibilidad ante las personas y los acontecimientos, sólo rota en algunos poemas (de allí que en las últimas décadas haya una tendencia a recuperarlo como poeta, faceta opacada por la del narrador).

Lo mismo que expulsa del texto a la infidencia cruda-todo está elaborado por una prosa magistral- también expulsa la vibración emotiva y la profundidad existencial: éstas tienen algo, para ellos, de mal gusto, de incómodo exhibicionismo. ¿Hasta qué punto muchas páginas de este 
diario son fragmentos de una crónica de sociales de la alta burguesía argentina? Una de las cosas que impresiona de ese genio insensible es la desprotección (no sólo física), la necesidad de tener cerca a su madre y a sus amigos (o a su sustituto en sus parejas sentimentales, palabra que casi habría que poner entre comillas), más dependiente incluso pero sin la homosexualidad de Lezama Lima.

La fama lo obligó a un ritmo que no era el suyo (y que no creo que disfrutara), de viajes, presentaciones públicas y homenajes; lo sacó incluso de esa rutina, que sí disfrutaba, de su amistad con Bioy, evidente en la espaciación de las entradas del diario en la última década.

Para tratarnos de acercar al final propondré un par de preguntas: ¿qué representa este libro en la literatura biográfica latinoamericana y qué representa en la obra de Bioy Casares? Empezamos por lo segundo; ya se tenían noticias de la abundante práctica del diarismo en el autor de $L a$ guerra del cerdo; se hablaba de más de 17,000 páginas, de lo cual se puede suponer que este Borges es al menos un $20 \%$. Sin embargo, como ya se dijo, Bioy no se destacó como escritor memorialista, los escritos biográficos directos e indirectos no se pueden comparar con su obra narrativa. A pesar de ello, y a pesar de que -por su volumen e importancia-Borges será motivo de muchas discusiones de toda índole, yo me atrevería a decir que se trata de la obra magna de Bioy Casares, en la que pulveriza la falta de aliento que lo lastraba en sus cuentos y en algunas novelas, y que además lo distancia totalmente de su admirado amigo en el terreno literario (en el otro, la verdad no creo que tenga interés).

Situarlo en el contexto latinoamericano es más difícil, no sólo porque no es un dominio geográficoidiomático en el que haya destacadas obras maestras sino también porque en los últimos tiempos se han publicado piezas importantes que aún no valoramos plenamente -los diarios de Alejandra Pizarnik y Julio Ramón Ribeyro, la aburridísima autobiografía de Ernesto Cardenal, las memorias de Gabriel García Márquez, los cuadernos de Tomás Segovia-, pero que ya permiten establecer ciertas diferencias. Para Bioy el diario es un registro no un laboratorio -como lo era para Kafka o Valery- y, sin importar el afrancesamiento que algunos le cuelgan, no tiene nada que ver con el género de los Cahiers, no es tampoco un testimonio histórico ni una ventana al mundo sino a sí mismo, y en este caso a Borges.

¿Era posible construir, después de Borges, otro Borges? Y no me refiero a ése que está y no está, o está de muchas maneras, como fantasma 
NOTAS

desdoblado en sus poemas, sino a un Borges en la pluma de otro (se han hecho intentos innumerables). Sí lo consiguió, y pienso que sin traicionarlo. Es el que aparece en estas páginas: el plenamente literario, lector compulsivo, conversador brillante, y también un escritor plenamente humano, lejos de la imagen olímpica ya vuelta muy convencional. Un Borges que nos durará todavía escribiendo y escribiéndose a sí mismo. 